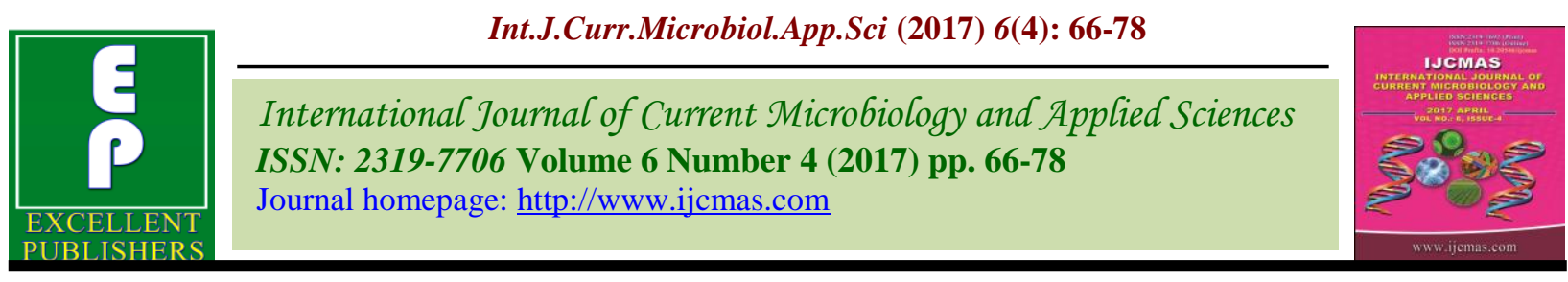

Review Article

https://doi.org/10.20546/ijcmas.2017.604.009

\title{
Resistance/Tolerance Mechanism under Water Deficit (Drought) Condition in Plants
}

\author{
Omprakash $^{1 *}$, R. Gobu ${ }^{1}$, Prashant Bisen ${ }^{1}$, Murlimanohar Baghel ${ }^{2}$ and \\ Kumar Nishant Chourasia ${ }^{3}$
}

\author{
${ }^{1}$ Department of Genetics and Plant Breeding, B.H.U., Varanasi (U.P.), India \\ ${ }^{2}$ Division of Fruits and Horticultural Technology, ICAR-IARI, New Delhi-110 012, India \\ ${ }^{3}$ Department of Genetics and Plant Breeding, G.B.P.U.A.T. Pantnagar, Uttarakhand, India \\ *Corresponding author
}

\begin{tabular}{|c|c|}
\hline & A B S T R A C T \\
\hline & \multirow{6}{*}{$\begin{array}{l}\text { Drought is a shortfall of water availability sufficient to cause loss in yield. Agricultural } \\
\text { drought is a situation where the moisture supply is inadequate to meet the requirement of } \\
\text { the crop. To cope with the drought, resistant/tolerant plants initiate defense strategies } \\
\text { against water deficit, which are categorized as morphological and } \\
\text { physiochemical/biochemical mechanisms. Plant drought tolerance involves changes at } \\
\text { whole-plant, tissue, physiological and molecular levels. Manifestation of a single or a } \\
\text { combination of inherent changes determines the ability of the plant to sustain itself under } \\
\text { limited moisture supply. Drought escape, drought avoidance, phonological flexibility are } \\
\text { the main attributes in morphological mechanisms and it can be achieved by early growth } \\
\text { vigour, reduced leaf area, high degree of leaf rolling, vigorous root system, epicuticular } \\
\text { wax deposition, presence of awns, hairiness etc. Osmotic adjustment, osmoprotection, } \\
\text { antioxidation and scavenging defense system have been the most important } \\
\text { physiochemical/biochemical bases responsible for drought tolerance. Cell tissue and water } \\
\text { conservation, antioxidant defense, cell membrane stability, compatible solutes and plant } \\
\text { growth regulators mainly contributes in above said physiochemical/biochemical } \\
\text { mechanisms. }\end{array}$} \\
\hline Keywords & \\
\hline $\begin{array}{l}\text { Drought, } \\
\text { Resistance, Cell } \\
\text { tissue and water } \\
\text { conservation. }\end{array}$ & \\
\hline Article Info & \\
\hline $\begin{array}{l}\text { Accepted: } \\
\text { 02 March } 2017 \\
\text { Available Online: } \\
10 \text { April } 2017\end{array}$ & \\
\hline & \\
\hline
\end{tabular}

\section{Introduction}

Drought is one of the major abiotic stresses in the world. Water stress from anthesis to maturity affects numerous morphological and physiological activities of plant resulting extensively reduces in crop yield and productivity (Bray, 1997; Hallajian, 2016). An extended period of deficient rainfall compared to normal rainfall of the region is called drought. Depending on the criteria used, drought is called as meteorological, agricultural or hydrological drought. Agricultural drought refers to extended dry period in which lack of rainfall results in insufficient moisture in the root zone of the soil causing adverse effect on crops. Drought stress, the major constrain for crop productivity, is affecting $1 / 3$ of arable land world-wide and will probably increase in the on-going climate changes. Therefore, future sustaining the productivity of land will be, at least partially, dependent on production of crops with increased drought tolerance or resistance. Drought resistance defined by Blum (1986) as "The mechanisms causing 
minimum loss of yield under water deficit environment related to the maximum yield in a water constraint free management of crop". Drought tolerance is defined as the ability to grow, flower and display economic yield under suboptimal water supply. Drought stress affects the water relations of plants at cellular, tissue and organ levels, causing specific as well as unspecific reactions, damage and adaptation reactions (Beck et al., 2007). Drought resistance is sometimes considered as a penalty towards yield potential, which is not necessarily the case. Molecular biologists entering this discipline often report the effect of an exotic gene towards 'drought tolerance' and advertise its expected value in breeding, which is rarely the case. Drought resistance and its components are almost constantly being redefined, whereas newcomers to this discipline often express outstanding inventive capacity for terminology. Drought resistance in its physiological context is defined according to Levitt (1972) being determined by 'dehydration avoidance' and/or 'dehydration tolerance'. Fang and Xiong (2015) divided the drought resistance of plants into four basic groups namely, drought avoidance, drought tolerance, drought escape, and drought recovery. 'Drought resistance' (DR) is a broader term applied to plant species with adaptive features that enable them to escape, avoid, or tolerate drought stress. However 'Drought escape' is the ability of a plant species to complete its life cycle before the onset of drought. 'Drought avoidance' is the ability of plants to maintain (relatively) higher tissue water content despite reduced water content in the soil (Levitt, 1972). Plants respond and adapt to and survive under drought stress by the induction of various morphological, biochemical and physiological responses. When a genotype yields better than another under a severe (below the 'crossover') strain of drought, it is said to be drought resistant/tolerance. Plant can adapt to drought either by avoiding or tolerating the stress through different mechanisms. In the natural habitat, the plants adapt to water deficit situation in the microclimate by wide range of mechanisms, ranging from array of morphological, physiological, and biochemical adaptations, as well as varies from transient responses to low soil moisture to major survival mechanisms of escape by early flowering in absence of seasonal rainfall (Bohnert et al., 1995; Basu et al., 2016). These mechanisms provide drought resistance or tolerance, but they may or may not reduce the productivity. In this review, we majorly concentrated on the most important morphological, physiological and biochemical attributes related with the drought resistance mechanisms in plants, and also sum up the advances regarding to drought response in plants.

\section{Mechanisms of drought resistance/ tolerance in plants}

World agricultural production and productivity is considerably reduced owing to the changing climate conditions and the diverse complexity of water limiting environment like, drought stress. The tolerant plant species have evolved a series of mechanisms at the morphological, physiological, biochemical, cellular, and molecular levels to overcome to cope up with such stress conditions (Bohnert et al., 1995; Chaves and Oliveira, 2004; Fang and Xiong, 2015). In the following sections, mechanisms of drought resistance/tolerance at different levels are presented.

\section{Morphological mechanisms}

Plant drought tolerance involves changes at whole-plant, tissue, physiological and molecular levels. Manifestation of a single or a combination of inherent changes determines 
the ability of the plant to sustain itself under limited moisture supply. An account of various morphological mechanisms operative under drought conditions is given below.

\section{Drought escape}

Escape from drought is attained through a shortened life cycle or growing season, allowing plants to reproduce before the environment becomes dry. Flowering time is an important trait related to drought adaptation, where a short life cycle can lead to drought escape (Araus et al., 2002). Crop duration is interactively determined by genotype and the environment which determines the ability of the crop to escape from climatic stresses including drought. Drought escape occurs when phenological development is successfully matched with periods of soil moisture availability, where the growing season is shorter and terminal drought stress predominates (Araus et al., 2002). In field-grown clones of robusta coffee, leaf shedding in response to drought stress occurred sequentially from older to younger leaves, suggesting that the more drought-sensitive the clone, the greater the extent of leaf shedding (DaMatta, 2004). Time of flowering is a major trait of a crop adaptation to the environment, particularly when the growing season is restricted by terminal drought and high temperatures. Developing short-duration varieties has been an effective strategy for minimizing yield loss from terminal drought, as early maturity helps the crop to avoid the period of stress (Kumar and Abbo, 2001). However, yield is generally correlated with the length of crop duration under favorable growing conditions, and any decline in crop duration below the optimum would tax yield (Turner et al., 2001).

\section{Drought avoidance}

Drought avoidance consists of mechanisms that reduce water loss from plants, due to stomatal control of transpiration, and also maintain water uptake through an extensive and prolific root system (Turner et al., 2001; Kavar et al., 2007). The root characters such as biomass, length, density and depth are the main drought avoidance traits that contribute to final yield under terminal drought environments (Subbarao et al., 1995; Turner et al., 2001). If tolerance is defined as the ability to maintain leaf area and growth under prolonged vegetative stage stress, the main basis of variation appears to be constitutive root system architecture that allows the maintenance of more favorable plant water status (Nguyen et al., 1997). Glaucousness or waxy bloom on leaves helps with maintenance of high tissue water potential, and is therefore considered as desirable trait for drought tolerance (Richards et al., 1986; Ludlow and Muchow, 1990). Varying degrees of glaucousness in wheat led to increased water use efficiency, but did not affect total water use or harvest index. Determination of leaf temperature indicated that, compared with non-glaucous leaves, glaucous leaves were $0.7{ }^{\circ} \mathrm{C}$ cooler and had a lower rate of leaf senescence (Richards et al., 1986). These authors suggested that a $0.5{ }^{\circ} \mathrm{C}$ reduction in leaf temperature for six hours per day was sufficient to extend the grain-filling period by more than three days. However, yield advantages are likely to be small as many varieties already show some degree of glaucousness. Early flowering will also ascribe escape of late-season stress, and reduced tillering may also ascribe deeper roots.

\section{Reduced water use}

Plants are developmentally and physiologically designed by evolution to reduce water use (WU) under drought stress. Since plant production is a function of WU, the issue for the breeder is how to reduce WU under stress while minimizing the associated 
reduction in production. It would seem that this is a question of the genetic scatter around the very firm regression of biomass production on crop water use. However, the regression of biomass on crop water use is itself can be changed. Water-use efficiency for grain yield is not a fixed crop entity. The rate of reduction in water use against the rate of reduction in yield as drought develops allows room for manipulations. This does not mean that WUE must be addressed by the breeder but rather by the dynamics of its nominator and denominator under stress. For example, reduced plant size, leaf area, and leaf area index (LAI) are a major mechanism for moderating water use and reducing injury under drought stress (Mitchell et al., 1998). Reduced growth duration is associated with reduced leaf number (Blum, 2004). The radiative energy load on the canopy (net radiation), of which only a fraction is used for photosynthesis, is dissipated mainly by transpiration. A reduction in transpiration can be achieved by reducing net radiation by way of reflection, namely increasing crop albedo. Various plant-surface structures allow an increase in albedo (Holmes and Keiller 2002). Reduced leaf chlorophyll content expressed in yellowish or pallid green shade of colour is indicative of reduced antenna complexes at the Photosystem II reaction centre. This reduces photosynthetically active radiation (PAR) absorption and subsequently water use. Such varieties were found adapted to dry and cold conditions (Watanabe et al., 1995). However, at the same time, these reflective properties that are beneficial under drought stress were often associated with reduced photosynthesis and yield potential (Premachandra et al., 1994; Sanchez et al., 2001).

\section{Phenotypic Flexibility}

Plant growth is greatly affected by water deficit. At a morphological level, the shoot and root are the most affected and both are the key components of plant adaptation to drought. Plants generally limit the number and area of leaves in response to drought stress just to cut down the water budget at the cost of yield loss (Schuppler et al., 1998). Since roots are the only source to acquire water from soil, the root growth, its density, proliferation and size are key responses of plants to drought stress (Kavar et al., 2007). It has long been established that plants bearing small leaves are typical of xeric environments. Such plants withstand drought very well, albeit their growth rate and biomass are relatively low (Ball et al., 1994). Leaf pubescence is a xeromorphic trait that helps protect the leaves from excessive heat load. Hairy leaves have reduced leaf temperatures and transpiration (Sandquist and Ehleringer, 2003). Under high temperature and radiation stress, hairiness increases the light reflectance and minimizes water loss by increasing the boundary layer resistance to water vapor movement away from the leaf surface. It is shown that active phloem supply of assimilates and associated water reserves from mature stems was the mechanism that allowed developing stems of Hylocereus undatus to maintain growth under drought conditions. Moreover, girdling the phloem of growing stems rapidly inhibited stem elongation, but secretion of sucrosecontaining nectar was maintained during drought. The water potential gradient was in the wrong direction for xylem transport from mature to young growing stems and axial hydraulic conductivity was low to negligible (Nerd and Neumann, 2004). Evidence related to root also suggests that it is quality, i.e. the distribution and structure, and not quantity of roots that determines the most efficient strategy for extracting water during the cropgrowing season. The drought tolerance of tea, onion and cotton was increased by improved root growth and root functioning. Selection for a deep and extensive root system has been 
advocated to increase productivity of food legumes under moisture-deficit conditions as it can optimize the capacity to acquire water (Subbarao et al., 1995). Studies carried out on the effects of alleles of the wheat shoot dwarfing genes on root-shoot dry matter partitioning and drought resistance revealed that cultivars possessing the reduced height gene 1 and reduced height gene 2 gibberellin insensitive dwarfing genes were more susceptible to drought stress than reduced height gene1 and reduced height gene 2 tall cultivars (Miralles et al., 1997). To summarize, plants may escape drought stress by cutting short their growth duration, and avoid the stress with the maintenance of high tissue water potential either by reducing water loss from plants or improved water uptake, or both. Some plants may reduce their surface area either by leaf shedding or production of smaller leaves. The root system of crop plants play a critical role while water deficit situation, the plants have unique feature of vigorous root growth at initial stage of drought condition facilitating better absorption of water from deep soil ( $\mathrm{Hu}$ and Xiong, 2014). The drought resistance of plants is also associated with the increased growth, length, weight, volume and density of plant roots of crops (Hammer et al., 2009), extensive root system and rooting depth (Dixon et al., 1980), the root/shoot ratio (Tavakol and Pakniyat, 2007; Ali et al., 2009), penetration ability of roots in soil (Mohamed et al., 2002).

\section{Leaf traits}

The morphological and physiological responses of leaves to drought stress are crucial to reduce water loss and promote water use efficiency. Most of the plants reduce transpiration by limiting leaf area of the plants. The total leaf area of plants is a product of number of branches of tillers, number of leaves per branch and individual leaf area. Water deficit reduce tillering or branching which in turn reduce the leaf area resulting in less transpiration. In grasses, the leaves roll or curl due to moisture stress and thus reduce the area exposed to solar radiation resulting in low transpiration. The leaf traits such as, adjusting orientation of leaf blades like, upright or erect leaves or leaf rolling behavior, rolled leaves etc (Stevenson and Shaw, 1971; Begg et al., 1980; Meyer and Walker, 1981; Ludlow and Bjorkman, 1984; Oosterhuis et al., 1985). Some tolerant plants have xeromorphic structures such as, smaller and thicker leaves, more epidermal trichomes, smaller and denser stomata, a thicker cuticle epidermis, thicker palisade tissue, a higher ratio of palisade to spongy parenchyma thickness, and a more developed vascular bundle sheath (Esau, 1960; Abdulrahaman and Oladele, 2011). Other leaf-associated traits such as epidermal hairs, cuticular wax, along with leaf water potential, relative water content, water loss rate, and canopy temperature (Hu and Xiong, 2014).

\section{Physiological/biochemical mechanisms}

Osmotic adjustment, osmoprotection, antioxidation and a scavenging defense system have been the most important bases responsible for drought tolerance. The physiological basis of genetic variation in drought response is not clear; in part, because more intricate mechanisms have been suggested. Some of these mechanisms are described below.

\section{Cell and tissue water conservation}

Cell decreases its osmotic potential trough osmotic adjustment, as a consequence, increases the gradient for water influx and maintenance of turgor. Improved tissue water status may be achieved through osmotic adjustment and/or changes in cell wall elasticity. This is essential for maintaining 
physiological activity for extended periods of drought. Wild melon plant survived drought by maintaining its water content without wilting of leaves even under severe drought. Drought stress in combination with strong light led to an accumulation of high concentrations of citrulline, glutamate and arginine in leaves of wild watermelon. The accumulation of citrulline and arginine may be related to the induction of dopamine receptor interacting protein gene 1, a homologue of the acetylornithine deacetylase gene in Escherichia coli, where it functions to incorporate the carbon skeleton of glutamate into the urea cycle (Yokota et al., 2002). It has been identified that among various mechanisms, osmotic adjustment, abscisic acid and induction of dehydrins may confer tolerance against drought injuries by maintaining high tissue water potential (Turner et al., 2001). Solute accumulation lowers the osmotic potential of the cell, which attracts water into the cell and helps with turgor maintenance. The maintenance of turgor despite a decrease in leaf water volume is consistent with other studies of species with elastic cell walls. Osmotic adjustment helps to maintain the cell water balance with the active accumulation of solutes in the cytoplasm, thereby minimizing the harmful effects of drought (Morgan, 1990). Osmotic adjustment is an important trait in delaying dehydrative damage in water-limited environments by continued maintenance of cell turgor and physiological processes (Taiz and Zeiger, 2006). The osmotic adjustment also facilitates a better translocation of pre-anthesis carbohydrate partitioning during grain filling (Subbarao et al., 2000), while high turgor maintenance leads to higher photosynthetic rate and growth (Ludlow and Muchow, 1990). In faba bean, determination of leaf water potential was useful for describing the drought effect, but was not suitable for discriminating tolerant from sensitive genotypes. This suggested that water potential was not the defining feature of the tolerance (Riccardi et al., 2001). Nevertheless, other studies opined that determination of leaf water status in the morning and water content in leaves in the afternoon were potentially useful for screening drought tolerance in chickpea (Pannu et al., 1993).

\section{Antioxidant defense}

The antioxidant defense system in the plant cell constitutes both enzymatic and nonenzymatic components. Enzymatic components include superoxide dismutase, catalase, peroxidase, ascorbate peroxidase and glutathione reductase. Non-enzymatic components contain cystein, reduced glutathione and ascorbic acid (Gong et al., 2005). In environmental stress tolerance, such as drought, high activities of antioxidant enzymes and high contents of non-enzymatic constituents are important.

The reactive oxygen species in plants are removed by a variety of antioxidant enzymes and/or lipid-soluble and water soluble scavenging molecules. The antioxidant enzymes being the most efficient mechanisms against oxidative stress (Farooq et al., 2008). Apart from catalase and super oxide dismutase (SOD), four enzymes (ascorbate peroxidase, dehydroascorbate reductase, mono dehydroascorbate reductase and glutathione reductase) are involved in the ascorbate-glutathione cycle, a pathway that allows the scavenging of superoxide radicals and $\mathrm{H}_{2} \mathrm{O}_{2}$ (Fazeli et al., 2007). Ascorbate peroxidase is a key antioxidant enzyme in plants (Orvar and Ellis, 1997) whilst glutathione reductase has a central role in maintaining the reduced glutathione pool during stress (Pastori et al., 2000).

Carotenoids and other compounds, such as abietane diterpenes, ascorbic acid, $\alpha$ tocopherol etc have received little attention 
despite their capacity to scavenge singlet oxygen and lipid peroxy radicals, as well as to inhibit lipid peroxidation and superoxide generation under dehydrative forces (Deltoro et al., 1998). The transcript of some of the antioxidant genes such as glutathione reductase or ascorbate peroxidase was higher during recovery from a water deficit period and appeared to play a role in the protection of cellular machinery against damage by reactive oxygen species (Ratnayaka et al., 2003). Carotenes form a key part of the plant antioxidant defense system (Wahid et al., 2007), but they are very susceptible to oxidative destruction. The $\beta$-carotene present in the chloroplasts of all green plants is exclusively bound to the core complexes of photosystem I and photosystem II. Protection against damaging effects of reactive oxygen species at this site is essential for chloroplast functioning. Here, $\beta$-carotene, in addition to functioning as an accessory pigment, acts as an effective antioxidant and plays a unique role in protecting photochemical processes and sustaining them (Havaux, 1998). A major protective role of $\beta$-carotene in photosynthetic tissue may be through direct quenching of triplet chlorophyll, which prevents the generation of singlet oxygen and protects from oxidative damage.

\section{Cell membrane stability}

Biological membranes are the first target of many abiotic stresses. It is generally accepted that the maintenance of integrity and stability of membranes under water stress is a major component of drought tolerance in plants (Bajji et al., 2002). Cell membrane stability, reciprocal to cell membrane injury, is a physiological index widely used for the evaluation of drought tolerance (Premachandra et al., 1991). Moreover, it is a genetically related phenomenon since quantitative trait loci for this have been mapped in drought-stressed rice at different growth stages (Tripathy et al., 2000).
Cell membrane stability declined rapidly in Kentucky bluegrass exposed to drought and heat stress simultaneously (Wang and Huang, 2004). In a study on maize, $\mathrm{K}$ nutrition improved the drought tolerance, mainly due to improved cell membrane stability (Gnanasiri et al., 1991). The causes of membrane disruption are unknown; notwithstanding, a decrease in cellular volume causes crowding and increases the viscosity of cytoplasmic components. This increases the chances of molecular interactions that can cause protein denaturation and membrane fusion. For model membrane and protein systems, a broad range of compounds have been identified that can prevent such adverse molecular interactions. Some of these are proline, glutamate, glycinebetaine, carnitine, mannitol, sorbitol, fructans, polyols, trehalose, sucrose and oligosaccharides (Folkert et al., 2001). Another possibility of ion leakage from the cell may be due to thermal induced inhibition of membrane-bound enzymes responsible for maintaining chemical gradients in the cell (Reynolds et al., 2001). Arabidopsis leaf membranes appeared to be very resistant to water deficit, as shown by their capacity to maintain polar lipid contents and the stability of their composition under severe drought (Gigon et al., 2004).

\section{Plant growth regulators}

Previous studies revealed that major phytohormones, such as abscisic acid (ABA), cytokinin (CK), gibberellic acid (GA), auxin, and ethylene, regulate various processes which facilitate plant adjustment to drought stress (Wilkinson et al., 2012; Basu et al., 2016).

Either endogenous (produced internally) or exogenous (as applied) level of plant growth regulators influences physiological processes of plants even at very minute concentrations (Morgan, 1990). Under drought, endogenous contents of auxins, gibberellins and cytokinin 
usually decrease, while those of abscisic acid and ethylene increase (Nilsen and Orcutte, 1996). Nevertheless, phytohormones play vital roles in drought tolerance of plants.

Auxins induce new root formation by breaking root apical dominance induced by cytokinins. As a prolific root system is vital for drought tolerance, auxins have an indirect but key role in this regard. Drought stress limits the production of endogenous auxins, usually when contents of abscisic acid and ethylene increase (Nilsen and Orcutte, 1996).Nevertheless, exogenous application of indole-3--acetic acid (IAA) enhanced net photosynthesis and stomatal conductance in cotton (Kumar et al., 2001). Recently, it was revealed that Indole-3-butyric acid synthetase from Arabidopsis is also drought-inducible (Ludwig-Müller, 2007). Experiments with IBA and ethylene glycoltetra-acetic acid suggested that calcium and auxin participate in signaling mechanisms of drought-induced proline accumulation (Sadiqov et al., 2002).

Drought rhizogenes is an adaptive strategy that occurs during progressive drought stress and is reported from Brassicaceae and related families by the formation of short, tuberized, hairless roots. These roots are capable of withstanding a prolonged drought period and give rise to a new functional root system upon rehydration. The drought rhizogenesis was highly increased in the gibberrelic acid biosynthetic mutant ga5, suggesting that some gibberrelic acids might also participate in this process (Vartanian et al., 1994). Abscisic acid is a growth inhibitor and produced under a wide variety of environmental stresses, including drought. All plants respond to drought and many other stresses by accumulating abscisic acid. Abscisic acid is ubiquitous in all flowering plants and is generally recognized as a stress hormone that regulates gene expression and acts as a signal for the initiation of processes involved in adaptation to drought and other environmental stresses. It has been proposed that abscisic acid and cytokinin have opposite roles in drought stress. Increase in abscisic acid and decline in cytokinins levels favor stomatal closure and limit water loss through transpiration under water stress (Morgan, 1990). Abscisic acid alters the relative growth rates of various plant parts such as increase in the root-to-shoot dry weight ratio, inhibition of leaf area development and production of prolific and deeper roots (Sharp et al., 1994). It triggers the occurrence of a complex series of events leading to stomatal closure, which is an important water-conservation response (Turner et al., 2001).

ABA is the major hormone synthesized in roots and translocated to leaves to initiate adaptation of plants to drought stress through stomatal closure and reduced plant growth (Wilkinson et al., 2010). Abscisic acid induces expression of various water stress related genes. In a recent study, Zhang et al., (2005) reported a regulatory role of telomeric repeat binding factor gene 1 in abscisic acid sensitivity and drought response during seedling development. Bray (1997) suggested the existence of abscisic acid-dependent and abscisic acid-independent transduction cascades and pathways to act as a signal of drought stress and the expression of specific water stress-induced genes. Ethylene has long been considered a growth inhibitory hormone, although it is involved in environmentally driven growth inhibition and stimulation (Taiz and Zeiger, 2006). The response of cereals to drought includes loss of leaf function and premature onset of senescence in older leaves. Ethylene may serve to regulate leaf performance throughout its lifespan as well as to determine the onset of natural senescence and mediate drought-induced senescence (Young et al., 2004). Recent studies suggest that growth promotion is a common feature in ethylene responses. To escape this adversity, 
plants can optimize growth and tolerate abiotic stresses such as drought, and this response also involves ethylene synthesis (Pierik et al., 2007).

Polyamines are known to have profound influence on plant growth and development. Being cationic, polyamines can associate with anionic components of the membrane, such as phospholipids, thereby protecting the lipid bilayer from deteriorating effects of stress (Bouchereau et al., 1999). There has been a growing interest in the study of polyamine participation in the defense reaction of plants against environmental stresses and extensive research efforts have been made in the last two decades. Many genes for enzymes involved in polyamine metabolism have been cloned from several species, and their expression under several stress conditions has been analyzed. For example, the apple spermidine synthase gene when over express edencodes high levels of spermidine synthase, which substantially improves abiotic stress tolerance including drought (Wen et al., 2007).

\section{Compatible solutes and osmotic adjustment}

One of the most common stress tolerance strategies in plants is the overproduction of different types of compatible organic solutes (Serraj and Sinclair, 2002). Compatible solutes are low molecular weight, highly soluble compounds that are usually nontoxic even at high cytosolic concentrations. Generally they protect plants from stress through different means such as contribution towards osmotic adjustment, detoxification of reactive oxygen species, stabilization of membranes, and native structures of enzymes and proteins. Osmotic adjustment is a mechanism to maintain water relations under osmotic stress. It involves the accumulation of a range of osmotically active molecules/ions including soluble sugars, sugar alcohols, proline, glycine, betaine, organic acids, calcium, potassium, chloride ions, etc. Under water deficit and as a result of solute accumulation, the osmotic potential of the cell is lowered, which attracts water into the cell and helps with the maintenance of turgor. By means of osmotic adjustment, the organelles and cytoplasmic activities take place at about a normal pace and help plants to perform better in terms of growth, photosynthesis and assimilate partitioning to grain filling (Ludlow and Muchow, 1990; Subbarao et al., 2000).

In conclusion this review effort has been made to define drought, drought resistance/tolerance and their mechanisms occurring under water deficit conditions. It would be appreciated that several plant mechanisms be found to be present in plants culminates in crop yield under water stress circumstances. Constitutively whole-plant traits have a major role in affecting plant water use and plant dehydration avoidance under stress. Future progress may well consist in improvements of the plant responses in given drought scenarios, but not in all of them simultaneously. This generates a need for the study of a very large number of combinations genes $\times$ site $\times$ environmental conditions.

\section{References}

Abdulrahaman, A. and Oladele, E. 2011. Response of trichomes to water stress in two species of Jatropha. Insight bot., 1: $15-21$.

Ali, M.A., Abbas, A., Niaz, S., Zulkiffal, M., Ali, S. 2009. Morphophysiological criteria for drought tolerance in sorghum (Sorghum bicolor.) at seedling and postanthesis stages. Int. J. Agric. Biol., 11: 674-680.

Araus, J.L., Slafer, G.A., Reynolds, M.P., Royo, C. 2002. Plant breeding and drought in C3 cereals: what should we breed for? 
Ann. Bot., 89: 925-940.

Bajji, M., Kinet, J., Lutts, S. 2002. The use of the electrolyte leakage method for assessing cell membrane stability as a water stress tolerance test in durum wheat, Plant Growth Regul., 36: 61-70.

Ball, R.A., Oosterhuis, D.M., Mauromoustakos, A. 1994. Growth dynamics of the cotton plant during water-deficit stress, Agron. J., 86: 788-795.

Basu, S., Ramegowda, V., Kumar, A. and Pereira, A. 2015. Plant adaptation to drought stress [version 1; referees: 3 approved] F1000Research 2016, 5(F1000 Faculty Rev):1554 (doi: 10.12688/f1000research.7678.1)

Begg, J., Turner, N. and Kramer, P. 1980. Morphological adaptations of leaves to water stress. Adaptation of plants to water and high temperature stress. Wiley, New York.

Beck, E.H., Fettig, S., Knake, C., Hartig, K., Bhattarai, T. 2007. Specific and unspecific responses of plants to cold and drought stress, J. Biosci., 32: 501-510.

Blum, A. 2004. Sorghum physiology. In 'Physiology and biotechnology integration for plant breeding'. Eds HT Nguyen, A Blum. pp. 141-223. Marcel Dekker: New York).

Bohnert, H.J., Nelson, D.E., Jensen, R.G. 1995. Adaptations to Environmental Stresses. Plant Cell, 7(7): 1099-111.

Bouchereau, A., Aziz, A., Larher, F., Tanguy, M. 1999). Polyamines and environmental challenges: Rec. Develop, Plant Sci., 140: 103-125.

Bray, E.A. 1997. Plant responses to water deficit, Trends Plant Sci., 2; 48-54.

Chaves, M.M., Oliveira, M.M. 2004. Mechanisms underlying plant resilience to water deficits: prospects for watersaving agriculture, J. Exp. Bot., 55: 23652384.

DaMatta, F.M. 2004. Exploring drought tolerance in coffee: a physiological approach with some insights for plant breeding, Braz. J. Plant Physiol., 16: 1-6.

Deltoro, V.I., Calatayud, A., Gimeno, C.,
AbadõÂa, A., Barreno, E. 1998. Changes in chlorophyll a fuorescence, photosynthetic $\mathrm{CO}_{2}$ assimilation and xanthophyll cycle interconversions during dehydration in desiccation-tolerant and intolerant liverworts, Planta, 207: 224228.

Dixon, R., Wright, G., Behrns, G., Teskey, R. and Hinckley, T. 1980. Water deficits and root growth of ectomycorrhizal white oak seedlings. Can. J. For. Res., 10: 545-548.

Esau, K. 1960. Anatomy of seed plants. Soil Sci., 90:149

Fang, Y. and Xiong, L. 2015. General mechanisms of drought response and their application in drought resistance improvement in plants. Cellular and Molecular Life Sci., 72(4): pp.673-689.

Farooq, M., Aziz, T., Basra, S.M.A., Cheema, M.A., Rehamn, H. 2008. Chilling tolerance in hybrid maize induced by seed priming with salicylic acid, J. Agron. Crop Sci., 194: 161-168.

Fazeli, F., Ghorbanli, M., Niknam, V. 2007. Effect of drought on biomass, protein content, lipid peroxidation and antioxidant enzymes in two sesame cultivars, Biol. Plant, 51: 98-103.

Folkert, A.H., Elena, A.G., Buitink, J. 2001. Mechanisms of plant desiccation tolerance, Trends Plant Sci., 6; 431-438.

Gigon, A., Matos, A., Laffray, D., Zuily-fodil, Y., Pham-Thi, A. 2004. Effect of drought stress on lipid metabolism in the leaves of Arabidopsis thaliana (Ecotype Columbia), Ann. Bot., 94: 345-351.

Gnanasiri, S.P., Saneoka, H., Ogata, S. 1991. Cell membrane stability and leaf water relations as affected by potassium nutrition of water stressed maize, J. Exp. Bot., 42: 739-745.

Gong, H., Zhu, X., Chen, K., Wang, S., Zhang, C. 2005. Silicon alleviates oxidative damage of wheat plants in pots under drought, Plant Sci., 169: 313-321.

Hallajian, M.T. 2016. Mutation Breeding and Drought Stress Tolerance in Plants. In: Drought Stress Tolerance in Plants, Vol 2 (pp. 359-383). Springer 
International Publishing.

Hammer, G.L., Dong, Z., McLean, G., Doherty, A., Messina, C., Schussler, J., Zinselmeier, C., Paszkiewicz, S. and Cooper, M. 2009. Can changes in canopy and/or root system architecture explain historical maize yield trends in the US corn belt? Crop Sci., 49: 299-312.

Havaux, M. 1998. Carotenoids as membrane stabilizers in chloroplasts, Trends in Plant Sci., 3: 147-151.

Holmes, M.G., Keiller, D.R. 2002. Effects of pubescence and waxes on the reflectance of leaves in the ultraviolet and photosynthetic wave bands: a comparison of a range of species. Plant, Cell and Environ., 25: 85-93. doi: 10.1046/j.13653040.2002.00779.x.

$\mathrm{Hu}, \mathrm{H}$. and Xiong, L. 2014. Genetic engineering and breeding of drought-resistant crops. Annu. Rev. Plant Biol., 65: 715-741.

Kavar, T., Maras, M., Kidric, M., Sustar-Vozlic, J., Meglic, V. 2007. Identification of genes involved in the response of leaves of Phaseolus vulgaris to drought stress, Mol. Breed. 21: 159-172.

Kumar, B., Pandey, D.M., Goswami, C.L., Jain, S. 2001. Effect of growth regulators on photosynthesis. Transpiration and related parameters in water stressed cotton, Biol. Plant, 44; 475-478.

Kumar, J., Abbo, S. 2001. Genetics of flowering time in chickpea and its bearing on productivity in the semi-arid environments, Adv. Agron., 72; 107-138.

Levitt, J. 1972. 'Responses of plants to environmental stresses.' (Academic Press: New York).

Ludlow, M.M. and Bjorkman, O. 1984. Paraheliotropic leaf movement in Siratro as a protective mechanism against drought induced damage to primary photosynthetic reactions: damage by excessive light and heat. Planta, 161: 505-518.

Ludlow, M.M., Muchow, R.C. 1990. A critical evaluation of traits for improving crop yields in water-limited environments, Adv. Agron., 43: 107-153.
Ludwig-Müller, J. 2007. Indole-3-butyric acid synthesis in ecotypes and mutants of Arabidopsis thaliana under different growth conditions, J. Plant Physiol., 164: 47-59.

Meyer, W.S. and Walker, S. 1981. Leaflet orientation in water-stressed soybeans. Agron. J., 73: 1071-1074.

Miralles, D.L., Slafer, G.A., Lynch, V. 1997. Rooting patterns in nearisogenic lines of spring wheat for dwarfism, Plant Soil, 197; 79-86.

Mitchell, J.H., Siamhan, D., Wamala, M.H., Risimeri, J.B., Chinyamakobvu, E., Henderson, S.A., Fukai, S. 1998. The use of seedling leaf death score for evaluation of drought resistance of rice. Field Crops Res., 55: 129-139. doi: 10.1016/S03784290(97)00074-9.

Mohamed, M.F., Keutgen, N., Tawfika, A.A., Noga, G. 2002. Dehydration-avoidance responses of tepary bean lines differing in drought resistance. J. Plant Physiol., 159: 31-38.

Morgan, P.W. 1990. Effects of abiotic stresses on plant hormone systems, in: Stress Responses in plants: adaptation and acclimation mechanisms, Wiley-Liss, Inc., pp. 113-146.

Nerd, A., Neumann, P.M. 2004. Phloem water transport maintains stem growth in a drought-stressed crop cactus (Hylocereus undatus), J. Am. Soc. Hortic. Sci., 129: 486-490.

Nguyen, H.T., Babu, R.C., Blum, A. 1997. Breeding for drought resistance in rice: Physilogy and molecular genetics considerations, Crop Sci., 37; 1426-1434.

Nilsen, E.T., Orcutte, D.M. 1996. Phytohormones and plant responses to stress, in: Nilsen E.T., Orcutte D.M. Eds.), Physiology of Plant under Stress: Abiotic Factors, John Wiley and Sons, New York, pp. 183-198.

Oosterhuis, D.M., Walker, S., Eastham, J. 1985. Soybean leaflet movements as an indicator of crop water stress. Crop Sci., 25: 1101-1106.

Orvar, B.L., Ellis, B.E. 1997. Transgenic 
tobacco plants expressing antisense RNA for cytosolic ascorbate peroxidase show increased susceptibility to ozone injury, Plant J., 11; 1297-1305.

Pannu, R.K., Singh, D.P., Singh, P., Chaudhary, B.D., Singh, V.P. 1993. Evaluation of various plant water indices for screening the genotypes of chickpea under limited water environment, Haryana J. Agron., 9: $16-22$.

Pastori, G., Foyer, C.H., Mullineaux, P. 2000. Low temperature-induced changes in the distribution of $\mathrm{H}_{2} \mathrm{O}^{2}$ and antioxidants between the bundle sheath and mesophyll cells of maize leaves, J. Exp. Bot., 51: 107-113.

Pierik, R., Sasidharan, R., Voesenek, L.A.C.J. 2007. Growth control by ethylene: adjusting phenotypes to the environment, J. Plant Growth Regul., 26; 188-200.

Premachandra, G.S., Saneoka, H., Kanaya, M., Ogata, S. 1991. Cell membrane stability and leaf surface wax content as affected by increasing water deficits in maize, $J$. Exp. Bot., 42: 167-171.

Ratnayaka, H.H., Molin, W.T., Sterling, T.M. 2003. Physiological and antioxidant responses of cotton and spurred anoda under interference and mild drought, $J$. Exp. Bot., 54: 2293-2305.

Reynolds, M.P., Oritz-Monasterio, J.I., Mc Nab, A. 2001. Application of physiology in wheat breeding, CIMMYT, Mexico.

Riccardi, L., Polignano, G.B., de Giovanni, C. 2001. Genotypic response of faba bean to water stress, Euphytica, 118; 39-46.

Richards, R.A., Rawson, H.M., Johnson, D.A. 1986. Glaucousness in wheat: its development, and effect on water-use efficiency, gas exchange and photosynthetic tissue temperatures, Aust. J. Plant Physiol., 13: 465-473.

Sadiqov, S.T., Akbulut, M., Ehmedov, V. 2002. Role of $\mathrm{Ca}^{2+}$ in drought stress signaling in wheat seedlings, Biochemistry-Moscow+ 67; 491-497.

Sanchez, F.J., Manzanares, M., de Andres, E.F., Tenorio, J.L., Ayerbe, L. 2001. Residual transpiration rate, epicuticular wax load and leaf colour of pea plants in drought conditions. Influence on harvest index and canopy temperature. European J. Agron., 15: 57-70. doi: 10.1016/S11610301 (01)00094-6.

Sandquist, D.R., Ehleringer, J.R. 2003. Population- and family-level variation of brittlebush (Encelia farinosa, Asteraceae. pubescence: its relation to drought and implications for selection in variable environments, Am. J. Bot., 90: 14811486.

Schuppler, U., He, P.H., John, P.C.L., Munns, R. 1998. Effects of water stress on cell division and cell-division-cycle-2-like cell-cycle kinase activity in wheat leaves, Plant Physiol., 117: 667-678.

Serraj, R., Sinclair, T.R. 2002. Osmolyte accumulation: can it really help increase crop yield under drought conditions? Plant Cell Environ., 25: 333-341.

Sharp, R.E., Wu, Y., Voetberg, G.S., Soab, I.N., LeNoble, M.E. 1994. Confirmation that abscisic acid accumulation is required for maize primary root elongation at low water potentials, J. Exp. Bot., 45: 17431751.

Stevenson, K. and Shaw, R. 1971. Effects of leaf orientation on leaf resistance to water vapor diffusion in soybean (Glycine max L. Merr. leaves. Agron. J., 63: 327-329

Subbarao, G.V., Johansen, C., Slinkard, A.E., Rao, R.C.N., Saxena, N.P., Chauhan, Y.S. 1995. Strategies and scope for improving drought resistance in grain legumes, Crit. Rev. Plant Sci., 14: 469-523.

Subbarao, G.V., Nam, N.H., Chauhan, Y.S., Johansen, C. 2000. Osmotic adjustment, water relations and carbohydrate remobilization in pigeonpea under water deficits, J. Plant Physiol., 157; 651-659.

Taiz, L., Zeiger, E. 2006. Plant Physiology, 4th Ed., Sinauer Associates Inc. Publishers, Massachusetts.

Tavakol, E. and Pakniyat, H. 2007. Evaluation of some drought resistance criteria at seedling stage in wheat (Triticum aistivum L. cultivars. Pak. J. Biol. Sci., 10: $1113-1117$ 
Tripathy, J.N., Zhang, J., Robin, S., Nguyen, T.T., Nguyen, H.T. 2000. QTLs for cellmembrane stability mapped in rice (Oryza sativa L.) under drought stress, Theor. Appl. Genet., 100: 1197-1202.

Turner, N.C., Wright, G.C., Siddique, K.H.M. 2001. Adaptation of grain legumes pulses. to water-limited environments, $A d v$. Agron., 71: 123-231.

Vartanian, N., Marcotte, L., Ciraudat, J. 1994. Drought Rhizogenesis in Arabidopsis thaliana: differential responses of hormonal mutants, Plant Physiol., 104: 761-767.

Wahid, A., Gelani, S., Ashraf, M., Foolad, M.R. 2007. Heat tolerance in plants: an overview, Environ. Exp. Bot., 61: 199223.

Wang, Z., Huang, B. 2004. Physiological Recovery of Kentucky bluegrass from simultaneous drought and heat stress, Crop Sci., 44; 1729- 1736.

Watanabe, N., Naruse, J., Austin, R.B., Morgan, C.L. 1995. Variation in thylakoid proteins and photosynthesis in Syrian landraces of barley. Euphytica, 82: 213-220. doi: 10.1007/BF00029563.

Wen, X.P., Pang, X.M, Matsuda, N., Kita, M., Inoue, H., Hao, Y.J., Honda, C., Moriguchi, T. 2007. Over-expression of the apple spermidine synthase gene in pear confers multiple abiotic stress tolerance by altering polyamine titers, Transgenic Res., 17: 251-263.

Wilkinson, S., Davies, W.J. 2010. Drought, ozone, ABA and ethylene: new insights from cell to plant to community. Plant Cell Environ., 33(4): 510-25.

Wilkinson, S., Kudoyarova, G.R., Veselov, D.S., et al., 2012. Plant hormone interactions: innovative targets for crop breeding and management. J. Exp. Bot., 63(9): 3499-509.

Yokota, A., Kawasaki, S., Iwano, M., Nakamura, C., Miyake, C., Akashi, K. 2002. Citrulline and DRIP-1 Protein (ArgE Homologue. in Drought Tolerance of Wild Watermelon, Ann. Bot., 89; 825832.

Young, T.E., Meeley, R.B., Gallie, D.R. 2004. ACC synthase expression regulates leaf performance and drought tolerance in maize, Plant J., 40: 813-825.

Zhang, X., Zhang, Z., Chen, J., Chen, Q., Wang, X., Huang, R. 2005. Expressing TERF1 in tobacco enhances drought tolerance and abscisic acid sensitivity during seedling development, Planta, 222: 494-501.

\section{How to cite this article:}

Omprakash, R. Gobu1, Prashant Bisen, Murlimanohar Baghel and Kumar Nishant Chourasia. 2017. Resistance/Tolerance Mechanism under Water Deficit (Drought) Condition in Plants. Int.J.Curr.Microbiol.App.Sci. 6(4): 66-78. doi: https://doi.org/10.20546/ijcmas.2017.604.009 